\title{
Serum Level of Ferritin and Fibrinogen as Prognostic Indicator for Acute Ischemic Stroke
}

\author{
Rizk M. Khodeir, Maged K. Fahim, Mohamed H. El-Azab, Mohamed A. Helmy
}

\begin{abstract}
Department of Neurology, Benha faculty of medicine, Benha University, Egypt.
\end{abstract}

Correspondence to:

Mohamed A. Helmy, Department of Neurology, Benha faculty of medicine, Benha University, Egypt.

Email:

dr.mh123@yahoo.com

Received: 28 March 2021

Accepted: 2 May 2021

\author{
Abstract:
}

Background: Stroke is the main cause of disability worldwide, the second common cause of dementia and the second main cause of death after ischemic heart diseases. Acute phase response proteins i.e. ferritin, fibrinogen and others play an important role in the pathogenesis of ischemic stroke because acute cerebral ischemia triggers interleukin-6 release into cerebrospinal fluid and blood, which is a key mediator of acute phase reaction and induces synthesis of acute phase proteins during ischemia. Aim: This study aims to explore the correlation between serum ferritin and plasma fibrinogen levels and the neurological disability of acute ischemic stroke. Methods: This study was carried out in the Department of Neurology, Benha University from December 2019 to January 2021 to compare serum ferritin and plasma fibrinogen levels between a group of fifty stroke patients and fifty control, then to correlate their levels with clinical outcome in patients Results: Our study revealed that means of serum ferritin and plasma fibrinogen levels were 143.17 $\mathrm{ng} / \mathrm{ml}$ and $2.61 \mathrm{mg} / \mathrm{ml}$ in patients, while in control they were $78.36 \mathrm{ng} / \mathrm{ml}$ and $2.0 \mathrm{mg} / \mathrm{ml}$ respectively. We also found that high levels of ferritin and fibrinogen among cases were associated with poor outcome, as clarified by GCS and NIHSS scores and by infarct volume. Conclusion: It may be concluded that serum ferritin and plasma fibrinogen are significantly higher in AIS patients, and their elevated levels are associated with early neurological deterioration.

Key words: Ferritin, Fibrinogen,Stroke.

List of Abbreviations: AIS (acute ischemic stroke) 


\section{Introduction}

Stroke is a disorder characterized by rapidly developing clinical manifestations of focal, and at times global, loss of cerebral function, with symptoms lasting more than 24 hours or leading to death, with no apparent cause other than that of vascular origin. This definition includes cerebral infarction (ischemic stroke), non-traumatic intracerebral hemorrhage, intraventricular hemorrhage and most cases of subarachnoid hemorrhage [1].

It is assumed that the acute phase response proteins i.e. ferritin, fibrinogen and others play an important role in the pathogenesis of ischemic stroke because acute cerebral ischemia triggers interleukin-6 release into cerebrospinal fluid and blood, which is a key mediator of acute phase reaction and induces synthesis of acute phase proteins during ischemia [2].

Serum ferritin is a suitable index of the amount of cellular iron stores and consequently might be related to the availability of iron in the infarcted area. In brain tissue most of the non-heme iron is in the form of ferritin, which is localized in astrocytes and microglia. It is an acute phase response protein and its concentrations increases during inflammation [3].

The role of iron overload in stroke is poorly documented. However, high serum Ferritin on admission of acute stroke patients (within 24 to $48 \mathrm{~h}$ after stroke onset) was reported to predict a bad prognosis [4, 5 and 6$]$.

Serum ferritin has gained a great clinical interest in recent times, and is now under research as an important prognostic indicator of stroke. This has also enhanced research in the therapeutic role of iron chelation in improving stroke prognosis [7,

\section{8 and 9].}

Fibrinogen is an important component of the coagulation cascade, as well as a major determinant of blood viscosity and blood flow. It is a high molecular weight plasma adhesion protein and a biomarker of inflammation. Increased levels of fibrinogen result in changes in blood rheological properties that exacerbate the complications in peripheral blood circulation during stroke [10 and 11].

Several studies showed that elevated plasma fibrinogen level is associated with worse functional outcome after stroke $[12,13,14$ and 15]. 


\begin{abstract}
Aim of Work:
This study aims to explore the correlation between serum ferritin and plasma fibrinogen levels and the neurological disability of acute ischemic stroke.
\end{abstract}

\section{Subjects and methods:}

This study is a combined study; case control then prospective study.

It was conducted during the period from December 2019 to January 2021 upon 50 patients and 50 controls. The patients were recruited from Benha University Hospital. The control group was chosen to be age and sex matched and apparently healthy.

This study gained the approval of ethical committee and the verbal consents of the patients.

Inclusion Criteria were; acute ischemic cerebral infarction confirmed by CT scan, age ranges from 18-80 years, both sexes were included; patients presented within 48 hours from onset, patients who agreed to join the study according to the ethical considerations.

Exclusion Criteria were; hemorrhage revealed by CT scan, infection and inflammation, malignancy, anemia, age below 18 years or above 80 years, patients with chronic kidney disease or liver cell failure.

All patients were subjected to; thorough medical and neurological examination, routine laboratory investigations including CBC, liver and kidney function tests, Serum ferritin and plasma fibrinogen levels measured within 48 hours from onset of symptoms and assessed by ELISA (Enzymelinked Immunosorbent Assay), CT scan on brain, infarct volume measurement using $\mathrm{ABC} / 2$ method, Disability assessment on admission and after one week using: NIHSS, MRS, GCS. Data was analyzed with the help of SPSS version 26.

\section{Results:}

Table (1): Comparison between case and control groups

It showed that when comparing Case and Control groups there were:

- No statistically significant difference regarding age and sex distribution (P $>0.05)$.

- While serum ferritin and plasma fibrinogen showed a high statistically significant positive correlation $(\mathbf{p}<\mathbf{0 . 0 1})$. 
Table (2): Ferritin level and cases prognosis according to different scores

- We divided stroke patients according to serum ferritin into two groups (normal ferritin group/ elevated ferritin group).

1. By measuring GCS on admission and after one week; we found that only (4.3\%) of cases worsened in the normal ferritin group, while (50\%) of cases worsened in the high ferritin group according to GCS $(\mathbf{p}<\mathbf{0 . 0 5})$.

2. By measuring NIHSS on admission and after one week; we found that only $(4.3 \%)$ of cases worsened in the normal ferritin group, while (50\%) of cases worsened in the high ferritin group according to NIHSS $(\mathbf{p}<\mathbf{0 . 0 5})$.

3. By measuring MRS on admission and after one week; we found that $(2.2 \%)$ of cases worsened in the normal ferritin group, while $(0 \%)$ of cases worsened in the high ferritin group according to MRS (P >0.05).

Table (3): Infarct volume in relation to serum ferritin

- The patients with elevated serum ferritin showed a larger infarct volume with a mean of $34 \mathrm{cc}$, compared to patients with normal ferritin where the mean was $17.22 \mathrm{cc},(\mathbf{p}<\mathbf{0 . 0 1})$.
Table (4): Fibrinogen level and cases prognosis according to different scores

- We divided stroke patients according to plasma fibrinogen into two groups (normal fibrinogen group/ elevated fibrinogen group).

1. By measuring GCS on admission and after one week; we found that only $(4.3 \%)$ of cases worsened in the normal fibrinogen group, while $(50 \%)$ of cases worsened in the high fibrinogen group according to GCS $(\mathbf{p}<\mathbf{0 . 0 5})$.

2. By measuring NIHSS on admission and after one week; we found that only $(4.3 \%)$ of cases worsened in the normal fibrinogen group, while $(50 \%)$ of cases worsened in the high fibrinogen group according to NIHSS $(\mathbf{p}<\mathbf{0 . 0 5})$.

3. By measuring MRS on admission and after one week; we found that $(0 \%)$ of cases worsened in the normal fibrinogen group, while $(25 \%)$ of cases worsened in the high fibrinogen group according to MRS (P >0.05).

\section{Table (5): Infarct volume in relation to} plasma fibrinogen

- The patients with elevated plasma fibrinogen level showed a larger infarct volume with a mean of 33.5 cc, compared to patients with normal 
fibrinogen where the mean was positive correlation $(\mathbf{p}<\mathbf{0 . 0 1})$.

$17.26 \mathrm{cc}$, with a high significant

Table (1): Comparison between case and control groups

\begin{tabular}{|c|c|c|c|c|c|c|}
\hline & \multicolumn{2}{|c|}{ Case group (50) } & \multicolumn{2}{|c|}{ Control group (50) } & \multirow{2}{*}{$\begin{array}{l}\text { Statistical } \\
\text { test (x2) }\end{array}$} & \multirow[t]{2}{*}{$P$ value } \\
\hline & No & $\%$ & No & $\%$ & & \\
\hline \multicolumn{7}{|l|}{ Sex } \\
\hline Male & 32 & 64.0 & 31 & 62.0 & 0.04 & 0.84 \\
\hline Female & 18 & 36.0 & 19 & 38.0 & & \\
\hline Age (yrs) mean \pm SD & \multicolumn{2}{|c|}{$61.74 \pm 10.01$} & \multicolumn{2}{|c|}{$60.48 \pm 8.00$} & St $\mathrm{t}=0.70$ & 0.76 \\
\hline S. ferritin $(\mathrm{ng} / \mathrm{ml})$ mean $\pm \mathrm{SD}$ & \multicolumn{2}{|c|}{$143.17 \pm 72.31$} & \multicolumn{2}{|c|}{$78.36 \pm 18.96$} & St $\mathrm{t}=6.13$ & $<0.001 * *$ \\
\hline P. fibrinogen $(\mathrm{mg} / \mathrm{dL})$ mean $\pm \mathrm{SD}$ & \multicolumn{2}{|c|}{$2.61 \pm 1.07$} & \multicolumn{2}{|c|}{$2.0 \pm 0.33$} & St $\mathrm{t}=3.87$ & $<0.001 * *$ \\
\hline
\end{tabular}

Table (2): Ferritin level and cases prognosis according to different scores

\begin{tabular}{|c|c|c|c|c|c|c|}
\hline & \multicolumn{2}{|c|}{$S$ ferritin $\leq 250$} & \multicolumn{2}{|c|}{$S$ ferritin $>250(4)$} & \multirow{2}{*}{$\begin{array}{l}\text { Statistical test } \\
\text { (FET) }\end{array}$} & \multirow[t]{2}{*}{$P$ value } \\
\hline & No & $\%$ & No & $\%$ & & \\
\hline \multicolumn{7}{|c|}{ Score changes after $1 \mathrm{w}$} \\
\hline \multicolumn{7}{|c|}{ GCS changes $\mathrm{n}(\%)$} \\
\hline Worsened & 2 & 4.3 & 2 & 50 & 6.51 & $0.034^{*}$ \\
\hline Improved & 12 & 26.1 & 0 & 0.0 & & \\
\hline No change & 32 & 69.6 & 2 & 50 & & \\
\hline NIHSS changes & & & & & & \\
\hline Worsened & 2 & 4.3 & 2 & 50 & 6.35 & $0.049^{*}$ \\
\hline Improved & 37 & 80.5 & 2 & 50 & & \\
\hline No change & 7 & 15.2 & 0 & 0.0 & & \\
\hline MRS changes & & & & & & \\
\hline Worsened & 1 & 2.2 & 0 & 0.0 & 1.12 & 1.0 \\
\hline Improved & 24 & 52.2 & 2 & 50 & & \\
\hline No change & 21 & 45.6 & 2 & 50 & & \\
\hline
\end{tabular}

Table (3): Infarct volume in relation to serum ferritin

\begin{tabular}{ccccc}
\hline & $\begin{array}{c}\text { S ferritin } \leq \mathbf{2 5 0} \\
\mathbf{( 4 6 )}\end{array}$ & $\begin{array}{c}\text { S ferritin }>\mathbf{2 5 0} \\
(\mathbf{4})\end{array}$ & $\begin{array}{c}\text { Statistical test } \\
(\mathbf{S t ~ t})\end{array}$ & P value \\
\hline $\begin{array}{c}\text { Infarct Volume }(\mathbf{c c}) \\
\text { Mean } \pm \text { SD }\end{array}$ & $17.22 \pm 9.32$ & $34 \pm 2.83$ & 8.51 & $<0.001^{* *}$ \\
\hline
\end{tabular}


Benha medical journal, vol. 38, issue 2, 2021

Table (4): Fibrinogen level and cases prognosis according to different scores

\begin{tabular}{|c|c|c|c|c|c|c|}
\hline & \multicolumn{2}{|c|}{$\begin{array}{l}\text { P fibrinogen }<4.5 \\
(\mathrm{mg} / \mathrm{dL})(46)\end{array}$} & \multicolumn{2}{|c|}{$\begin{array}{l}\text { P fibrinogen }>4.5 \\
(\mathrm{mg} / \mathrm{dL})(4)\end{array}$} & \multirow{2}{*}{$\begin{array}{l}\text { Statisti } \\
\text { cal test } \\
\text { (FET) }\end{array}$} & \multirow[t]{2}{*}{$\begin{array}{l}P \\
\text { value }\end{array}$} \\
\hline & No & $\%$ & No & $\%$ & & \\
\hline \multicolumn{7}{|l|}{$\begin{array}{l}\text { Score changes after } 1 w \\
\text { GCS changes } \mathrm{n}(\%)\end{array}$} \\
\hline Worsened & 2 & 4.3 & 2 & 50.0 & $\mathrm{FET}=$ & $0.034 *$ \\
\hline Improved & 12 & 26.1 & 0 & 0.0 & 6.51 & \\
\hline No change & 32 & 69.6 & 2 & 50.0 & & \\
\hline \multicolumn{7}{|l|}{ NIHSS changes $\mathrm{n}(\%)$} \\
\hline Worsened & 2 & 4.3 & 2 & 50.0 & $\mathrm{FET}=$ & $0.012 *$ \\
\hline Improved & 39 & 84.8 & 0 & 0.0 & 8.84 & \\
\hline No change & 5 & 10.9 & 2 & 50.0 & & \\
\hline \multicolumn{7}{|l|}{ MRS changes $n(\%)$} \\
\hline Worsened & 0 & 0.0 & 1 & 25.0 & $\mathrm{FET}=$ & 0.14 \\
\hline Improved & 26 & 56.5 & 0 & 0.0 & 3.96 & \\
\hline No change & 20 & 43.5 & 3 & 75.0 & & \\
\hline
\end{tabular}

Table (5): Infarct volume in relation to plasma fibrinogen

\begin{tabular}{ccccc}
\hline & $\begin{array}{c}\text { P fibrinogen }<4.5 \\
(\mathbf{4 6})\end{array}$ & $\begin{array}{c}\text { P fibrinogen }>\mathbf{4 . 5} \\
\mathbf{( 4 )}\end{array}$ & $\begin{array}{c}\text { Statistical } \\
\text { test (St t) }\end{array}$ & P value \\
\hline $\begin{array}{c}\text { Infarct Volume }(\mathbf{c c}) \\
\text { Mean } \pm \text { SD }\end{array}$ & $17.26 \pm 9.42$ & $33.5 \pm 0.71$ & 11.33 & $<0.001^{* *}$ \\
\hline
\end{tabular}

\section{Discussion:}

In the present study, we found that the serum ferritin level was high in patients with acute ischemic stroke and ranged from 46.8 to $287.7 \mathrm{ng} / \mathrm{ml}$ with a mean of 143.17 (S.D \pm 72.31), while ferritin level in the healthy control group ranged from 40 to $110 \mathrm{ng} / \mathrm{ml}$ with a mean of 78.36 (S.D \pm 18.96$)$. We also found that the plasma fibrinogen level was high in patients with acute ischemic stroke and ranged from 1.55 to $5.56 \mathrm{mg} / \mathrm{ml}$ with a mean of 2.61 (S.D \pm 1.07$)$, while fibrinogen in controls ranged from 1.55 to $2.60 \mathrm{mg} / \mathrm{dL}$ with a mean of $2.0(S . D \pm 0.33)$ with a high statistically significant positive correlation $(\boldsymbol{p}<0.01)$. These results in agreement with previous studies which showed that serum ferritin and plasma fibrinogen levels were $83.1 \mathrm{ng} / \mathrm{ml}$ and $190.6 \mathrm{mg} / \mathrm{dl}$ in subjects with acute ischemic stroke, while in control subjects were $41.3 \mathrm{ng} / \mathrm{ml}$ and $177.0 \mathrm{mg} / \mathrm{dl}$ respectively [16].

Our study also found a statistically significant positive correlation $(\boldsymbol{p}<\mathbf{0 . 0 5})$ 
regarding serum ferritin level and changes in GCS and NIHSS scores (where these changes reflect the prognosis in term of improvement, worsening or no change). In cases with normal ferritin levels; GCS showed that $(4.3 \%)$ worsened after 1 week compared to cases with high ferritin level where $(50 \%)$ worsened. In cases with normal ferritin; NIHSS showed that (4.3\%) worsened after 1 week compared to cases with high ferritin level where $(50 \%)$ worsened. We also found a statistically significant positive correlation $(p<0.05)$ regarding the plasma fibrinogen level and changes in GCS and NIHSS scores. In cases with normal fibrinogen levels; GCS showed that $(4.3 \%)$ worsened after 1 week compared to cases with high fibrinogen level where $(50 \%)$ worsened. In cases with normal fibrinogen; NIHSS showed that $(4.3 \%)$ worsened after 1 week compared to cases with high fibrinogen where $(50 \%)$ worsened.

These results in agreement with previous study which showed that high ferritin level was associated with poor outcome in stroke patients, disability was measured within 48 hours of stroke onset and on day six [17], the study which found that the serum ferritin has direct correlation with worse prognosis in patients of stroke. The mean level of serum ferritin in the group of clinically improved (87.01) was much lesser compared to the group clinically deteriorated or died (458.7) among patients of ischemic stroke [18], the study which observed positive correlation between serum ferritin and NIHSS scores $(P=0.000)$ [19], the study which also revealed that there was a significant correlation between the values of serum ferritin and NIHSS $(P<0.001)$ and modified Rankin score $(P<0.001)$ [20], the study which suggested that fibrinogen can be involved as a risk factor for acute ischemic stroke and its prognosis [21], the scientists who found that the baseline fibrinogen level $\geq 450 \mathrm{mg} / \mathrm{dL}$ was significantly associated with poor functional outcome at 90 days even taking into account the covariates of age and pretreatment stroke severity [12 and 22], the study which evaluated fibrinogen levels in 200 patients with acute carotid artery distribution ischemic strokes who were treated with intravenous rtPA. They found that patients with fibrinogen levels $>360 \mathrm{mg} / \mathrm{dL}$ had poorer outcomes on discharge based on (NIHSS) scores and higher three-month mortality [23].

In contrast to our results, this study showed that the determination of ferritin level in CSF had no practical value in the evaluation of patients with meningeal 
reaction and cerebrovascular events [24], another study founded no association with either univariate or multivariate analyses between mortality at 1 year and fibrinogen levels obtained within 12 hours of symptom onset in a mixed group of hospitalized patients with cerebrovascular disease [25].

Serum ferritin and plasma fibrinogen also has a high statistically significant positive correlation $(p<0.01)$ with the volume of infarction, this is in agreement with the study which showed a significant correlation between the infarct volume and fibrinogen levels $(r$ coefficient $=0.61 ; p<0.05)[26]$.

\section{Conclusion:}

According to these data, we suggest that serum ferritin and plasma fibrinogen levels are powerful predictors of vascular events. Their elevated levels are associated with increased risk of stroke.

There is an association between serum ferritin and plasma fibrinogen elevated levels and stroke prognosis, where the elevated levels were found to be predictive of poor outcome.

\section{References:}

[1] Warlow C, Sudlow C, Dennis M. Stroke. Lancet 2003;362(9391):1211-24.

[2] Dziedzic T: Clinical significance of acute phase reaction in stroke patients. Front Biosci 2008, 13(24), 2922-2927.

[3] World Health Organization: Serum ferritin concentrations for the assessment of iron status and iron deficiency in populations (No. WHO/NMH/NHD/MNM/11.2). World Health Organization, 2011

[4] Davalos, A., Fernandez-Real, J. M., Ricart, W., Soler, S., Molins, A., Planas, E., \& Genis, D.: Iron-related damage in acute ischemic stroke,1994. Stroke, 25(8), 1543-1546.

[5] Davalos A, Castillo J, Marrugat J, FernandezReal JM, Armengou A, Cacabelos P. Rama R: Body iron stores and early neurological deterioration in acute cerebral infarction 2000. Neurology.54:1568-1574.

[6] Erdemoglu, A. K. and Ozbakir S.: Serum ferritin levels and early prognosis of stroke 2002. European journal of neurology, 9(6), 633-637.

[7] Walters, G. O., Miller, F. M. and Worwood, M.: Serum ferritin concentration and iron stores in normal subjects 1973. Journal of Clinical Pathology, 26(10), 770-772.

[8] Herbert V., Jayatilleke E., Shaw S., Rosman A. S., Giardina P. and Grady R. W. et al: Serum ferritin iron, a new test, measures human body iron stores unconfounded by inflammation 1997. Stem Cells, 15(4), 291 296.

[9] Mehdiratta M., Kumar S., Hackney D., Schlaug G. and Selim M.: Association between serum ferritin level and perihematoma edema volume in patients with spontaneous intracerebral hemorrhage 2008. Stroke, 39(4), 1165-1170. 
[10] Di Minno G., Cerbone A., Margaglione M., Vecchione G., Grandone E. and Mancini M.: Fibrinogen and mechanisms of thrombosis 1992. A difficult link. European journal of epidemiology, 8(1), 88-91.

[11] Abdelgawad D. M., Elbassiouny A. A., Youssef R. A., Eldin N. S. and Elrakawy M. H.: Elevated Plasma Fibrinogen Levels Predict Poor Clinical Outcome after Acute Ischemic Stroke 2014. Egyptian Journal of Neurology, Psychiatry \& Neurosurgery, 51(1).

[12] Del Zoppo G. J., Levy D. E., Wasiewski W. W., Pancioli A. M., Demchuk A. M. and Trammel, J. et al: Hyperfibrinogenemia and functional outcome from acute ischemic stroke 2009. Stroke, 40(5), 1687-1691.

[13] William Whiteley, Wei Li Chong and Anshuman Sengupta: Blood Markers for the Prognosis of Ischemic Stroke A Systematic Review Stroke 2009.40: e380e389

[14] van den Herik, E. G., Cheung, E. Y., de Lau, L. M., den Hertog, H. M., Leebeek, F. W. and Dippel, D. W. et al: $\gamma^{\prime} /$ total fibrinogen ratio is associated with short-term outcome in ischaemic stroke 2011. Thrombosis and haemostasis, 105(03), 430-434.

[15] Swarowska, M., Janowska, A., Polczak, A., Klimkowicz-Mrowiec, A., Pera, J., Slowik, A., and Dziedzic, T.: The sustained increase of plasma fibrinogen during ischemic stroke predicts worse outcome independently of baseline fibrinogen level 2014. Inflammation, 37(4), 1142-1147.

[16] SK Mandal, M Majumder and MS Hossain: serum ferritin and plasma fibrinogen level in acute ischemic stroke, Bangladesh $\mathrm{J}$ Med Biochem 2017; 10(1): 16-20
[17] Siddharth Kapoor, Parijat Mishra, Manish Narayan and Sanjay Kumar Singh, prognosis of patients in acute ischemic stroke and its assoc. with serum ferritin, International Journal of Scientific Research August - 2019, 8:8, 53-55

[18] Pranjal Pankaj, Medha Das and Manish Kumar Singh. "Association between Level of Serum Ferritin and Outcome of Patients of Stroke". Journal of Evolution of Medical and Dental Sciences 2015; Vol. 4, Issue 12, February 09; Page: 2003-2016, DOI: $10.14260 /$ jemds/2015/292

[19] Egovindarajulu K, Maaran AT, Prathiba P and Saiprashanth PR. A study on prognostic significance of serum ferritin in patients with acute ischemic stroke. IOSR J Dent Med Sci. 2016;15:31-9.

[20] Koul RK, Yaseen Y, Amreen S, Shah PA and Hakeem MM. Role of serum ferritin in determining the severity and prognosis of stroke: A hospital based study. Int J Sci Stud. 2017;6:142-5.

[21] Shao-Yuan Chuang, Chyi-Huey Bai, WeiHung Chen, Li-Ming Lien and Wen-Harn Pan; Fibrinogen independently predicts the development of ischemic stroke, STROKEAHA journals Mar2009,40:15781584

[22] Di Napoli M, Papa F and Bocola V., Prognostic influence of increased C-reactive protein and fibrinogen levels in ischemic stroke 2001. Stroke; 32:133-138.

[23] González-Conejero R, Fernandez-Cadenas I and Iniesta JA, Role of fibrinogen levels and factor XIII V34L polymorphism in thrombolytic therapy in stroke patients 2006. Stroke;37:2288-2293

[24] Milman N, Grandal NA, Olsen TS, Wandall JH and Pedersen NS, Cerebrospinal fluid in patients with meningitis and cerebral infarction or bleeding 1993. Dan Med Bull 40:490-492. 
[25] Lip GY, Blann AD and Farooqi IS, Sequential alterations in haemorheology, endothelial dysfunction, platelet activation and thrombogenesis in relation to prognosis following acute stroke: The West Birmingham Stroke Project 2002. Blood Coagul Fibrinolysis; $13:(339-347)$

To cite this article: Rizk M. Khodeir, Maged K. Fahim, Mohamed H. El-Azab, Mohamed A. Helmy. Serum Level of Ferritin and Fibrinogen as Prognostic Indicator for Acute Ischemic Stroke. BMFJ 2021;38(2): 559-568. DOI: 10.21608/bmfj.2021.68906.1402 